\title{
For how long will defined benefit liabilities continue to grow?
}

Received (in revised form): 21st February, 2008

\section{Santiago Caballero}

works as an economics analyst within the Research Team at Watson Wyatt Worldwide. Before joining Watson Wyatt in 2006, he worked as an assistant economist for the Central Bank of Uruguay. He holds a degree in Economics and at present is taking his MPhil in International Economics at the Faculty of Social Sciences in Montevideo, Uruguay. He is currently working on behavioural economics and risk applied to pensions.

\begin{abstract}
Many pension markets are experiencing a transition from defined benefit (DB) to defined contribution (DC) schemes, with most of the former being closed, frozen or wound up. Against this backdrop, this paper aims to calculate the DB market's future growth, but approaching the problem from the liabilities' side. We develop a general model whereby we can project DB liabilities based on the expected future trends in longevity, membership dynamics and salary growth. We then can deduce the expected future evolution of DB liabilities, which, if tied to assets, may be seen as an approach to predict the pension asset management market in the future. We apply this model to the UK pensions market. The main result is that even if all UK DB schemes are considered closed, DB liabilities still show a growing trend until the year 2017, reaching a maximum of 39 per cent above their current level and only returning to their current level around 2035.
\end{abstract}

Pensions (2008) 13, 15-23. doi:10.1057/pm.2008.2

Keywords: closed, defined, benefit, schemes, Markov, chains

\section{Introduction}

Global pension markets are undergoing a noticeable transition, with many countries seeing a switch from defined benefits (DB) to defined contributions (DC). With many DB plans being closed to new entrants, this raises the question of how the DB market will evolve over time.

As of yet, however, there has been little work done on calculating the likely future path of pension liabilities in such an environment. One exception is Poterba et al.' ${ }^{1}$ work on the US market. These authors project the average level of DB benefits by age and cohort together with the likelihood of receiving benefits by age and year. By combining these projections with

Correspondence: Santiago Caballero, Watson Wyatt Worldwide, Biotec Plaza 006-008, Zonamerica Business Park Ruta 8, Km.17.500, Montevideo 91600, Uruguay.

Tel: + 59825182329 ext. 22

Fax: +598 25182329 ext. 19;

E-mail: santiago.caballero@watsonwyatt.com demographic trends, they estimate total DB pension benefits to be paid each year.

In this paper, we adopt a similar approach to analyse the likely evolution of liabilities in a world of closed DB plans. In line with Poterba et al., we divide the population into cohorts and estimate the probability of their continuing to belong to a DB plan in the future. We also use appropriate vesting schedules, wage growth expectations and annuity rates to convert the accumulated pension rights into an expected pension obligation. Our analysis, however, differs from Poterba et al. in two ways. First, our calculations are made assuming DB schemes are closed to new entrants; Poterba et al. use figures extrapolated from historical data. Secondly, while they work with money and inflation, our model is built explicitly in real terms, considering values in the initial period as numeraires and examining relative changes from this position. We thus aim to build a model that may allow the estimation of DB liabilities within an economy or firm, based 
on the appropriate demographic, pension and labour market assumptions.

More specifically, the assumptions used in this work are the following:

1. Salary increases due to tenure

2. Initial level of accumulated pension rights

3. Expectation of life of people above 65 years (increases with time)

4. A fixed wage growth rate

5. A fixed long-term interest rate

6. A factor reflecting the drift in annuity rates bought at the age of retirement.

The purpose of this paper is to first present the model in general terms, and then focus on the UK pension market. In the first section, we name and define the different assumptions and parameters of the model, whereas in the second section we introduce specific UK values to estimate the evolution of DB liabilities there.

\section{The model}

Our approach is to consider a model in which the initial population considered are all DB schemes members and we assume that these plans are closed to new entrants. Hence, we discuss a baseline comparative model where we examine how DB liabilities can be expected to evolve in a closed world, relative to the current situation. As it is a baseline model, we assume the current level of pension is a numeraire (ie set to 1), and we examine changes from this level.

\section{Liability base}

We first focus on current pensioners and estimate their already accrued liabilities. To perform this, we consider the accumulated rights of initial pensioners at the moment of reaching retirement age. We assume that this population, during its working period, belonged to $\mathrm{DB}$ plans with graded vesting requirement. This means that the longer the individual is within a plan, the more accumulated the rights he or she obtains.

On reaching retirement age, these rights are multiplied by the average expectation of life of all pensioners to come up with the total initial Liability Base $\left(L_{0}\right)$ :

$$
L_{0}^{P}=S_{0}^{P} \sum_{x=65}^{X} \omega_{x} E\left(T_{x}\right)
$$

where $S_{0}^{P}$ represents all accumulated rights up to the age of 65 by current pensioners, called initial service; $T_{x}$, the future lifetime for an individual aged $x$; $E\left(T_{x}\right)$, the expected future lifetime for this individual; and $\omega_{x}$, the weight of individuals aged $x$ in the total pensioners' population.

We now focus on active employees, with the objective of calculating their accrued DB liabilities for the years ahead. We thus depart from the employees' initial Liability Base $\left(L_{0}^{E}\right)$ by simplifying equation (1), only considering the accumulated rights till the initial year, again assuming graded vested requirement:

$$
L_{0}^{E}=S_{0}^{E}
$$

\section{Liability ratio}

We now start building a dynamic model to predict DB future coverage. ${ }^{2}$ As the probability of belonging to a DB plan in one period depends on belonging to it in the previous period, we assume this process could be represented as a Markov Chain process with the following transition matrix:

$$
\begin{aligned}
P_{t+1} \times X_{t} & =X_{t+1}^{\prime} \Rightarrow\left(\begin{array}{cc}
\operatorname{Pr}\left(D B_{t+1}^{E} \mid D B_{t}^{E}\right) & 0 \\
\operatorname{Pr}\left(N D B_{t+1}^{E} \mid D B_{t}^{E}\right) & 1
\end{array}\right)\left(\begin{array}{l}
D B_{t}^{E} \\
N D B_{t}^{E}
\end{array}\right) \\
& =\left(\begin{array}{l}
D B_{t+1}^{E} \\
N D B_{t+1}^{E}
\end{array}\right)
\end{aligned}
$$

where $\operatorname{Pr}\left(D B_{t+1}^{E} \mid D B_{t}^{E}\right)$ represents for the moment $t+1$, the probability of being in a DB plan; and $\operatorname{Pr}\left(N D B_{t+1}^{E} \mid D B_{t}^{E}\right)$, the probability of not being in a DB plan, given that the individual is in a DB scheme at moment $t$.

Thus, when applied to all ages, we obtain the DB schemes' coverage $\left(C_{t+1}^{E}\right)$ in the following periods (see Appendix A):

$$
C_{t+1}^{E}=D B_{t+1}^{E}
$$

The accumulated coverage in moment $t$ is referred to as service $\left(S_{t}^{E}\right)$. Thus, departing from the initial service $\left(S_{0}^{E}\right)$ based on the accumulated 
rights, we add the DB coverage for the following years and obtain the service in moment $t$. For simplicity, we assume the same accrual factor for all ages and periods.

$$
S_{t}^{E}=S_{0}^{E}+\sum_{t=1}^{t} C_{t}^{E}
$$

We now use the calculated variables to construct a total liability ratio for active employees by year. Then to consider the evolution of DB accrued liabilities, we take the previously defined service and coverage, its evolution year by year and incorporate a wage factor as another source of accruing liabilities. Therefore, ratio 1 is calculated as follows:

$$
\text { ratio }_{t}=\left(\frac{S_{t}^{E}}{S_{t-1}^{E}}\right)\left[\left(1-C_{t}^{E}\right)+\frac{\left(C_{t}^{E} w_{t}^{E}\right)}{w_{t-1}^{E}}\right]
$$

where $\left(S_{t}^{E} / S_{t-1}^{E}\right)$ shows the additional service being accumulated, $w_{t}^{E}, w_{t-1}^{E}$ represent the wages in the moment $t$ and $t+1$, respectively, having no real wage growth for deferred and positive real wage growth for active workers.

Finally, we assume that all members at retirement age buy an annuity which is payable for the remaining life of the pensioner, so we need to build a ratio that contemplates the annuity's drift in the future, proportional to population demographics.

We thus introduce ratio2:

$$
\text { ratio } 2_{t}=\frac{r_{t}}{r_{t-1}} \frac{\text { annuity rate }_{t}}{\text { annuity rate }_{t-1}}
$$

where $r$ is the discount rate, ${ }^{3}$ and annuity rate shows the stock of pensioners within the population in each period. We assume an initial annuity rate of 1 , and index its growth with the population's ageing.

We then build a liability ratio, using both ratios:-

$$
\text { ratio }_{t}=\text { ratio }_{t} \times \text { ratio }_{t}
$$

and calculate the liabilities for individuals aged 20-65 in moment $t$ by taking the liability base, and multiplying it for each ratio in the following years up to moment $t$ :

$$
L_{t}^{E}=L_{0}^{E} \prod_{t=1}^{t} \text { ratio }_{t}
$$

When each cohort reaches retirement age and for the following years, we also include a reduction factor based on mortality rates $\left(1-\delta_{t+j}\right)$ :

$$
L_{t}^{E}=L_{0}^{E} \prod_{t=1}^{t}\left[\text { ratio }_{t}\left(1-\delta_{t}\right)\right]
$$

\section{Total liabilities index}

Finally, to obtain the total DB liabilities per year we add the liabilities accrued by today's active workers plus liabilities accrued by current pensioners:

$$
\sum_{x=20}^{X} L_{t}=\sum_{x=20}^{x=64} L_{t, c}^{E}+\sum_{x=65}^{X} L_{t, x}^{E}
$$

and construct a total liabilities index $\left(L I_{t}\right)$, with base in year $2007\left(L_{07}\right)$, which contemplates the evolution of DB liabilities over time in real terms:

$$
L I_{t}=\frac{\sum_{x=20}^{X} L_{t}}{\sum_{x=20}^{X} L_{07}}
$$

\section{Case study: The UK pension market}

To apply the model of the previous section to the UK pension market, we must substitute the parameters for country-specific values.

\section{Liability base}

Recalling equation (1):

$$
L_{0}^{P}=S_{0}^{P} \sum_{x=65}^{X} \omega_{x} E\left(T_{x}\right)
$$

To calculate the initial service $\left(S_{0}^{P}\right)$, we assume that during the working period, the individual accumulates rights as follows:

- Aged 20-24: 20 per cent for the initial period and an additional 20 per cent for the subsequent years.

- Aged 24+:50 per cent for the initial period and an additional 50 per cent in the following years. 


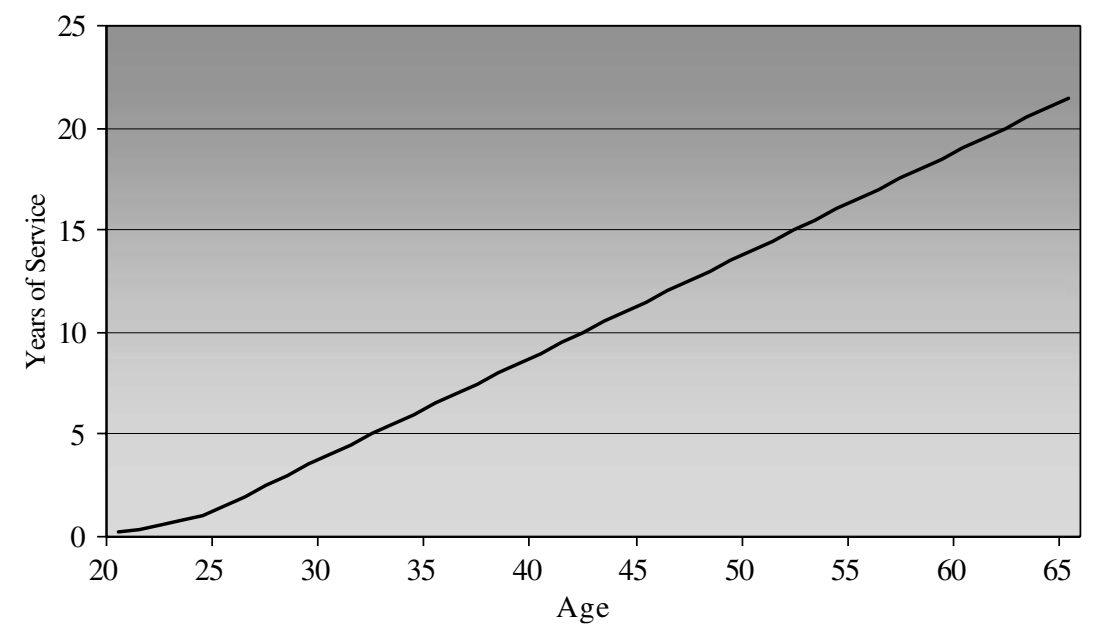

Figure 1: Accumulated rights for individuals within a DB scheme

This can be seen in Figure 1.

Thus, we assume the average 25-year-old worker who is currently in a DB plan would have accumulated two years of service (in that plan) and the average 36-year-old would have accumulated seven. This accounts for a broad average across the member population.

To obtain the sum, we first consider life expectancy in the UK by age (see Appendix B Table B1), match this with population projections by age (see Appendix B - Table B2) and obtain the weighted average expectation of life for current pensioners in the UK: 13 years (see Appendix B - Table B3).

\section{Liability ratio}

As mentioned in equation (8) the liability ratio is built upon two ratios: one based on service, coverage and wages; the other on reflecting an annuity component.

We thus first need to calculate the evolution of DB coverage and wages to obtain ratio 1 .

\section{Coverage}

The general trend shows that the older the person, the higher the probability of belonging to DB plans. We take the proportions of individuals belonging to a DB plan by age (see Appendix B - Table B4) and use this as our initial age structure in $\mathrm{DB}$ membership. We now calculate the probability of staying in the DB scheme year by year. As we are using a model in which there are no new scheme entrants, we will use the probability of staying in the same job as a proxy of the probability of staying in a DB plan (see Appendix B - Table B5). This also assumes DB plans have the same turnover probability as all jobs - if DB has retention advantages this will not be the case and liabilities will be higher, so again we are a lower bound.

\section{Wages}

We now aim to introduce wage growth into the model. In order to achieve this, we observe the Average Earnings Index Growth and inflation rates for the period 1991-2005. Figure 2 shows these series.

We thus obtain an average real wage growth of 2 per cent, which we use as proxy of the wage growth from 2007 onwards (see Appendix B Table B6).

We now add a tenure-component to the wage growth. A number of empirical papers suggest that wages grow with service in a company in addition to any effects from general labour market experience. ${ }^{4-6}$

In our model, as mentioned above we initially consider a base real wage growth of 2 per cent plus a tenure increase as follows:

- 1 per cent for each of first ten years in the same job.

- 0 per cent for $10+$ years in the same job.

To introduce the annuity component and calculate ratio2, we should estimate the amount of pensioners 


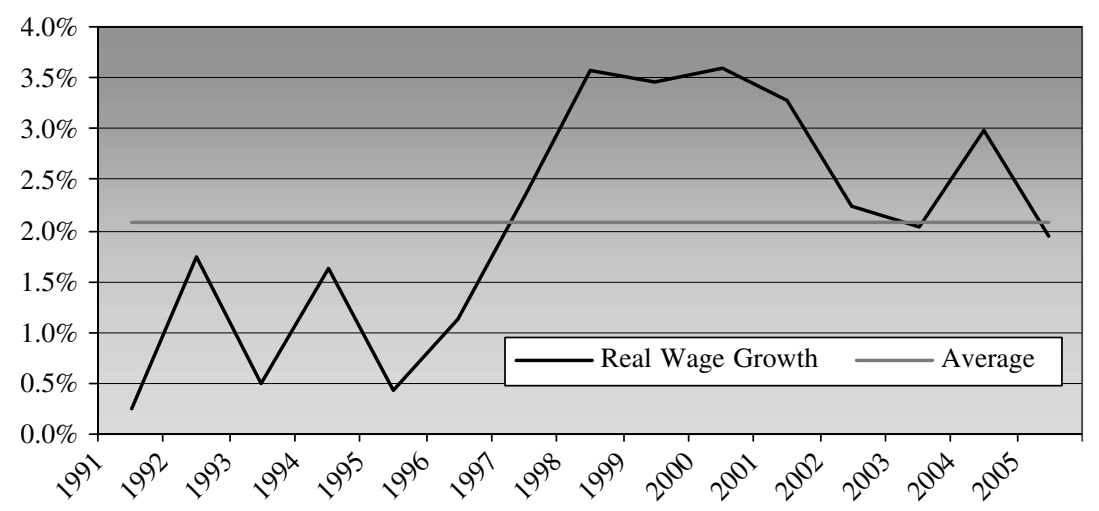

Figure 2: UK - real wage growth 1991-2005

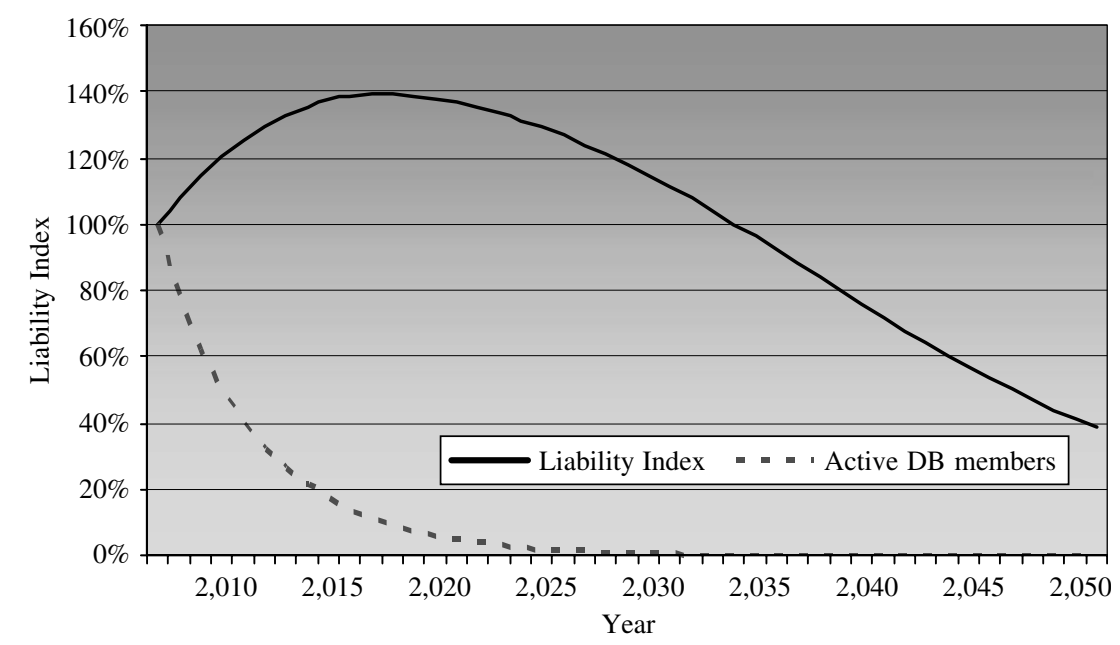

Figure 3: DB pension liabilities - UK

in the initial population. To understand the annuity's drift, we index its growth with the population's ageing. We thus use an initial annuity rate of 1 , and we consider a 1 per cent annuity rate growth.

The discount rate of 2.5 per cent is obtained from the average interest rates of gilts with different maturities. For simplicity's sake, this discount rate is assumed constant along the period of study. ${ }^{7}$ The final factor is years until retirement.

$$
r_{t}=\left(1+\text { longtermUK Gilt } t_{t}\right) e^{-y e a r s u n t i l \text { retirement }}
$$

\section{Total liabilities index}

Recalling equation (10) from the model, we calculate the accrued liabilities for each active employee in the moment $t$, and we add the current pensioners' calculations as in equation (11). For both populations, we take into consideration their mortality rates to estimate future liabilities. ${ }^{8}$

When we add current pensioners' liabilities plus active workers' liabilities and use 2007 as the base year, we obtain the total liabilities index for the UK.

This index shows a growing trend that reaches its maximum in year 2017, being 39 per cent above the initial value. From that year on, it starts a declining trend, which crosses the initial value by year 2035 .

Results are shown in Figure 3 and Table 1.

\section{Concluding remarks}

The transition from DB to DC schemes in the pensions market raises the question of how DB pensions will develop over time. This paper has 
Table 1: UK liabilities index by year

\begin{tabular}{|c|c|c|}
\hline Year & Liability index (\%) & DB active members (\%) \\
\hline 2007 & 100.0 & 100.0 \\
\hline 2008 & 107.9 & 77.7 \\
\hline 2009 & 114.7 & 61.5 \\
\hline 2010 & 120.4 & 49.2 \\
\hline 2011 & 125.6 & 39.7 \\
\hline 2012 & 129.9 & 32.1 \\
\hline 2013 & 133.2 & 26.0 \\
\hline 2014 & 135.6 & 21.1 \\
\hline 2015 & 137.4 & 17.2 \\
\hline 2016 & 138.5 & 13.9 \\
\hline 2017 & 139.1 & 11.3 \\
\hline 2018 & 139.1 & 9.2 \\
\hline 2019 & 138.6 & 7.4 \\
\hline 2020 & 137.8 & 6.0 \\
\hline 2021 & 136.6 & 4.9 \\
\hline 2022 & 135.2 & 3.9 \\
\hline 2023 & 133.5 & 3.1 \\
\hline 2024 & 131.4 & 2.5 \\
\hline 2025 & 129.2 & 2.0 \\
\hline 2026 & 126.7 & 1.6 \\
\hline 2027 & 124.0 & 1.2 \\
\hline 2028 & 121.1 & 1.0 \\
\hline 2029 & 118.1 & 0.8 \\
\hline 2030 & 114.8 & 0.6 \\
\hline 2031 & 111.3 & 0.5 \\
\hline 2032 & 107.7 & 0.4 \\
\hline 2033 & 104.0 & 0.3 \\
\hline 2034 & 100.1 & 0.2 \\
\hline 2035 & 96.2 & 0.2 \\
\hline 2036 & 92.2 & 0.1 \\
\hline 2037 & 88.1 & 0.1 \\
\hline 2038 & 84.0 & 0.1 \\
\hline 2039 & 79.9 & 0.1 \\
\hline 2040 & 75.8 & 0.0 \\
\hline 2041 & 71.8 & 0.0 \\
\hline 2042 & 68.0 & 0.0 \\
\hline 2043 & 64.2 & 0.0 \\
\hline 2044 & 60.6 & 0.0 \\
\hline 2045 & 57.1 & 0.0 \\
\hline 2046 & 53.7 & 0.0 \\
\hline 2047 & 50.4 & 0.0 \\
\hline 2048 & 47.2 & 0.0 \\
\hline 2049 & 44.1 & 0.0 \\
\hline 2050 & 41.2 & 0.0 \\
\hline
\end{tabular}

devised a model based on assumptions on demographic trends, the labour market and pension system within a particular country, to come up with an estimation of DB liabilities' evolution.

We apply this model in the UK by substituting each parameter for country-specific values. We adopted a conservative approach, assuming a negative framework, with values that include the public sector. The results showed a growing trend of DB liabilities, reaching their maximum by year 2017, 39 per cent above their value in 2007 ; declining after that point, and being under the present value by year 2035 .

This result implies that although there is a declining trend, workers who are already covered by these kinds of plans have accrued enough rights to keep the present size of the market for at least 28 years. If assets are tied to liabilities, this also gives an estimation of the scale of the pension asset management market in the future and how it will evolve.

Comparing this result with the study on the US market performed by Poterba et al., both countries will show a similar evolution in their pension liabilities: the authors also project for the US a growing trend of DB liabilities with a declining growth rate. Here, the maximum is reached in 2027, 30 per cent above the starting value and declining thereafter.

In reality, one major factor that would alter at what point the maximum value is reached regards new DB entrants. Our model assumed there are no new DB entrants, and this reduces the amount of accrued liabilities.

Also, when performing the assumptions, our values given to the parameters tend to be conservative. We do not account for the freezing of current members' rights or bulk buy-outs, both of which could hasten the decline.

Finally, it is important to note that although this analysis was performed at a general level, this model could be applied at a sector-specific level, or even at a micro-level, in a single pension plan.

\section{References and Notes}

1 Poterba, J., Venti, S. and Wise, D. A. (2007) 'The decline of defined benefit retirement plans and asset flows', National Bureau of Economic Research, Working paper 12834, Cambridge, US

2 The model is in real terms.

3 Based on Bank of England time-series on UK gilts of different maturities.

4 Williams $^{5}$ argues that during the first ten years in a job, wages increase by an average 1 per cent per year due to tenure. On the other hand, general labour experience has a higher impact on wages; the author claims that it may cause an increase of 60 per cent for the individual after 30 years of work. In an alternative analysis, Dustmann and Pereira ${ }^{6}$ calculate that ten years of job seniority generate about 6 per cent of wage benefits while in line with Williams' findings, the authors find that ten years of general labour experience account for nearly 70 per cent of the salary.

5 Williams, N. (2004) 'Seniority, Experience, and Wages in the UK', Department of Economics, University of Cincinnati, US. 
6 Dustmann, C. and Pereira, S. (2005) 'Wage growth and job mobility in the UK and Germany', Discussion paper no. 1586, Institute for the Study of Labour (IZA), Bonn, Germany.
7 Bank of England time-series.

8 Government Actuary's Department.

9 UK National Statistics (2006) '2006 Annual Survey of Hours and Earnings', Office for National Statistics, UK.

\section{Appendix A}

\section{Markov chain process}

The following matrix shows the proportion of $\mathrm{DB}$ and non-DB members in moment $t+1$ for individuals aged $x$ :

$$
\begin{aligned}
P_{t+1} \times X_{t} & =X^{\prime}{ }_{t+1} \Rightarrow\left(\begin{array}{cc}
\operatorname{Pr}\left(D B_{t+1}^{E} \mid D B_{t}^{E}\right) & 0 \\
\operatorname{Pr}\left(N D B_{t+1}^{E} \mid D B_{t}^{E}\right) & 1
\end{array}\right)\left(\begin{array}{l}
D B_{t}^{E} \\
N D B_{t}^{E}
\end{array}\right) \\
& =\left(\begin{array}{l}
D B_{t+1}^{E} \\
N D B_{t+1}^{E}
\end{array}\right)
\end{aligned}
$$

The resulting matrix, shows the proportion of DB and non-DB members in moment $t+1$ for individuals aged $x$.

Thus, when applied to all ages, it becomes:

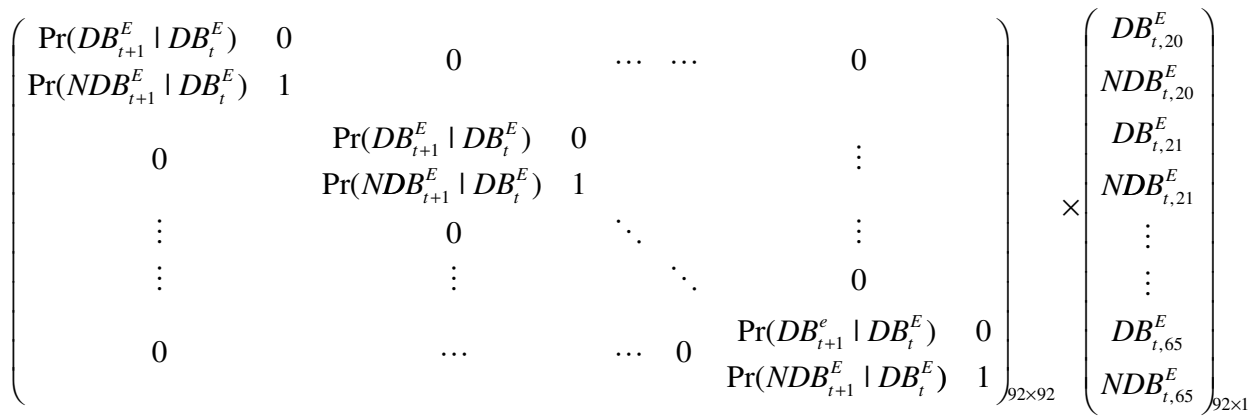

$$
\begin{aligned}
& =\left(\begin{array}{c}
D B_{(t+1), 21}^{E} \\
N D B_{(t+1), 21}^{E} \\
D B_{(t+1), 22}^{E} \\
N D B_{(t+1), 22}^{E} \\
\vdots \\
\vdots \\
D B_{(t+1), 66}^{E} \\
N D B_{(t+1), 66}^{E}
\end{array}\right)_{92 \times 1}
\end{aligned}
$$

As we are using a closed model where there are no new DB entrants, these probabilities must also consider that if the individual changes his or her job, s/he will be out of the DB scheme forever. We thus obtain the DB schemes' coverage by age in the following periods. 


\section{Appendix B}

\section{Tables - UK case study}

See Tables B1-B6

Table B1: Expectation of life

\begin{tabular}{lcc}
\hline \multicolumn{2}{l}{ United Kingdom } \\
\hline \multicolumn{2}{l}{ Period expectations of life (years) - GAD } \\
\hline Attained age & Males & Females \\
\hline 65 & 17.4 & 19.9 \\
70 & 13.7 & 15.8 \\
75 & 10.4 & 12.1 \\
80 & 7.7 & 9.0 \\
85 & 5.5 & 6.3 \\
90 & 3.9 & 4.4 \\
95 & 2.9 & 3.1 \\
\hline
\end{tabular}

Source: Government Actuary's Department.

Table B2: Population projections - 2007

\begin{tabular}{|c|c|c|c|}
\hline \multicolumn{4}{|c|}{ Population projections - GAD } \\
\hline \multicolumn{4}{|c|}{ United Kingdom - PERSONS, thousands } \\
\hline Ages & Total & Males & Females \\
\hline 65 & 564 & 273 & 291 \\
\hline 66 & 527 & 255 & 273 \\
\hline 67 & 545 & 263 & 282 \\
\hline 68 & 543 & 261 & 282 \\
\hline 69 & 533 & 256 & 278 \\
\hline 70 & 516 & 246 & 271 \\
\hline 71 & 496 & 234 & 262 \\
\hline 72 & 475 & 223 & 252 \\
\hline 73 & 449 & 208 & 241 \\
\hline 74 & 438 & 201 & 237 \\
\hline 75 & 430 & 195 & 236 \\
\hline 76 & 420 & 186 & 234 \\
\hline 77 & 399 & 174 & 225 \\
\hline 78 & 374 & 160 & 214 \\
\hline 79 & 348 & 147 & 201 \\
\hline 80 & 333 & 138 & 195 \\
\hline 81 & 315 & 127 & 188 \\
\hline 82 & 290 & 114 & 176 \\
\hline 83 & 269 & 103 & 167 \\
\hline 84 & 247 & 91 & 156 \\
\hline 85 & 234 & 84 & 150 \\
\hline 86 & 219 & 75 & 143 \\
\hline 87 & 190 & 64 & 126 \\
\hline 88 & 128 & 42 & 87 \\
\hline 89 & 93 & 29 & 65 \\
\hline $90-94$ & 320 & 87 & 233 \\
\hline $95-99$ & 84 & 18 & 66 \\
\hline 100 \& over & 11 & 2 & 9 \\
\hline Total & 9,794 & 4,253 & 5,541 \\
\hline Total 18-64 & 37,994 & 18,901 & 19,093 \\
\hline Pop 65+/pop 18-64 & $26 \%$ & $23 \%$ & $29 \%$ \\
\hline
\end{tabular}

Source: Government Actuary's Department 
Table B3: Weighed average expectation of life calculations by age and sex

\begin{tabular}{|c|c|c|c|c|c|c|c|}
\hline \multicolumn{8}{|c|}{ Average expectation of life - United Kingdom - Pop aged 65+ } \\
\hline Age & Pop 2007 (th) & $\%$ & Males (th) & Life Exp & Females (th) & Life Exp & Pop Life Exp \\
\hline $65-69$ & 2,712 & 28 & 1,307 & 17.4 & 1,405 & 19.9 & 18.7 \\
\hline $70-74$ & 2,375 & 24 & 1,111 & 13.7 & 1,264 & 15.8 & 14.8 \\
\hline $75-79$ & 1,972 & 20 & 862 & 10.4 & 1,110 & 12.1 & 11.4 \\
\hline $80-84$ & 1,455 & 15 & 572 & 7.7 & 882 & 9.0 & 8.5 \\
\hline $85-89$ & 864 & 9 & 293 & 5.5 & 571 & 6.3 & 6.0 \\
\hline $90-94$ & 320 & 3 & 87 & 3.9 & 233 & 4.4 & 4.3 \\
\hline 95-99 & 84 & 1 & 18 & 2.9 & 66 & 3.1 & 3.1 \\
\hline 100 \& over & 11 & 0 & 2 & & 9 & NA & NA \\
\hline Total 65+ & 9,794 & & & & & Average & 13.0 \\
\hline
\end{tabular}

Source: UK National Statistics.

Table B4: Pension participation by age

\begin{tabular}{|c|c|c|c|}
\hline \multicolumn{4}{|c|}{ Pension type - All employee jobs } \\
\hline \multicolumn{4}{|c|}{ United Kingdom, 2006} \\
\hline Age & $D B(\%)$ & NDB (\%) & NPP (\%) \\
\hline $16-21$ & 6 & 8 & 86 \\
\hline $22-29$ & 23 & 18 & 59 \\
\hline $30-39$ & 36 & 24 & 40 \\
\hline $40-49$ & 45 & 22 & 34 \\
\hline $50-54$ & 46 & 21 & 33 \\
\hline $55-59$ & 42 & 21 & 37 \\
\hline $60-64$ & 29 & 22 & 49 \\
\hline $65+$ & 6 & 12 & 82 \\
\hline
\end{tabular}

Source: ASHE - UK National Statistics. ${ }^{9}$
Table B5: Employees in the same job in the last 12 months by age

\begin{tabular}{ll}
\hline $\begin{array}{l}\text { Proportions of employees in the same job as } 12 \text { months } \\
\text { ago by age group }\end{array}$ \\
\hline Great Britain; 1996-2001 \\
\hline Age & (\%) \\
\hline $18-24$ & 50 \\
$25-34$ & 75 \\
$35-49$ & 82 \\
50 and over & 87 \\
\hline
\end{tabular}

Source: UK National Statistics.

Table B6: Average earnings growth/inflation rates

\begin{tabular}{lllllll}
\hline Year & AEl (seas adj) & AEl growth (\%) & CPI index & Inflation (\%) & AEI/CPI & Growth (\%) \\
\hline 1990 & 63.9 & & 71.5 & & 0.894 & \\
1991 & 68.8 & 7.7 & 76.8 & 7.4 & 0.896 & 0.2 \\
1992 & 73.0 & 6.1 & 80.1 & 4.3 & 0.911 & 1.7 \\
1993 & 75.2 & 3.0 & 82.1 & 2.5 & 0.916 & 0.5 \\
1994 & 78.0 & 3.7 & 83.8 & 2.1 & 0.931 & 1.6 \\
1995 & 80.4 & 3.1 & 86.0 & 2.6 & 0.935 & 0.4 \\
1996 & 83.3 & 3.6 & 88.1 & 2.4 & 0.946 & 1.1 \\
1997 & 86.8 & 4.2 & 89.7 & 1.8 & 0.968 & 2.3 \\
1998 & 91.3 & 5.2 & 91.1 & 1.6 & 1.002 & 3.6 \\
1999 & 95.7 & 4.8 & 92.3 & 1.3 & 1.037 & 3.5 \\
2000 & 100.0 & 4.5 & 93.1 & 0.9 & 1.074 & 3.6 \\
2001 & 104.5 & 4.5 & 94.2 & 1.2 & 1.134 & 3.3 \\
2002 & 108.2 & 3.5 & 95.4 & 1.3 & 1.157 & 2.2 \\
2003 & 111.9 & 3.4 & 96.7 & 1.3 & 1.192 & 2.0 \\
2004 & 116.8 & 4.4 & 100.0 & 2.0 & & 3.0 \\
2005 & 121.5 & 4.0 & & & Average & 2 \\
\hline
\end{tabular}

Source: UK National Statistics. 